\title{
Notas sobre La comunidad política vitalista de Darío Botero Uribe ${ }^{194}$
}

Agradezco profundamente la cordial invitación a participar en este evento y especialmente las palabras de Darío Botero en la dedicatoria de su libro, en la que me expresa su sincera amistad, que hago recíproca. Me ha invitado a un dialogo creativo como el que trataremos de emprender en las presentes notas sobre su libro La comunidad política vitalista, el cual he leído con suma atención y agrado.

Ante todo se trata de un libro bien escrito por un filósofo auténtico que sabe expresar sus ideas, como debe ser, con la profundidad teórica necesaria y a la vez la claridad requerida para hacerlas inteligibles y por tanto comprensibles, independientemente de que se pueda coincidir o no, total o parcialmente con ellas.

194 "En la interpretación que Zuleta hace de Marx, no considerada ya en términos negativos sino positivos, habría que resaltar el énfasis que pone en subrayar la valoración de la libertad y de la creatividad de la acción humana, en oposición a los férreos determinismos destacados por el marxismo vulgar". Valencia, A. En el principio era la ética... ensayo de interpretación del pensamiento de Estanislao Zuleta, Universidad del Valle, Cali, 1996, p. 132. 
El problema no consiste en estar de acuerdo o no con determinadas tesis sino desarrollar el ejercicio del filosofar y seguir construyendo utopías concretas para contribuir desde las trincheras intelectuales al mejoramiento de las sociedades. José Martí afirmaba que trinchera de ideas valen más que trincheras de piedras en tanto para Marx es necesario aproximar lo mejor posible lo ideal a lo real para que dialécticamente lo real se aproxime mejor a lo ideal.

El libro en cuestión puede considerarse que se inscribe en el género utópico, tema este que de vieja data ha sido preocupación y ocupación de Darío, pues según el "la utopía para mi es el rechazo de una realidad alienada y brutal y la posibilidad de construir una realidad nueva. La utopía no es en manera alguna la irrealidad sino la realidad posible que no hemos tenido todavía la imaginación o el coraje de construir" (Botero, 1994, pp. 1-2).

De manera que pensar utópicamente constituye un reto que presupone cuestionarse críticamente la realidad existente y concebir fórmulas para mejorarla. Acertadamente, con anterioridad había considerado que, "Las utopías son connaturales al hombre. La civilización no podría funcionar sin utopías. Las utopías ayudan a hacer soportable el proceso histórico. Enfrentadas a la cosificación, la brutalidad y la irracionalidad que juegan un papel importantísimo en la historia, permiten seguir construyendo la humanización o, por lo menos, mantener estable el nivel de humanización logrado." (Botero, 1994, p. 135). E imbuido de ese criterio emprende la tarea de elaborar su propia utopía.

Todo aquel que se da a la tarea de construir alguna que otra utopía es porque no se siente satisfecho con el mundo en que vive y se plantea transformarlo. Otra cuestión son las vías y objetivos que se plantee. Ese es el caso de Darío Botero, no solo con este libro sino con otros anteriores en los que ha formulado su concepción del vitalismo cósmico. En todos ellos se puede fácilmente apreciar su profundo desacuerdo con las sociedades existentes, tanto el presunto "socialismo real" como el, - muy distante de toda posible presuntuosidad, dada su capacidad para sobrevivir, lo cual no es prueba alguna de su justa existencia- "capitalismo real".

La filosofía históricamente ha desempeñado múltiples funciones: cosmológica, epistemológica, axiológica, ideológica, hegemónica, práctico educativa, ética, estética (Guadarrama, 1998a, pp. 22-34), entre otras, pero tal vez no se ha valorado bien hasta el presente su función crítico-utópica, pues 
ella no siempre se ha limitado a reflejar de algún modo la realidad de una época, como planteaba Hegel, sino también la formulación de propuestas de mejoramiento del ser humano y de las sociedades existentes, como en el caso de La República de Platón, La Utopía de Moro, La ciudad del sol de Campanella, La nueva Atlántida de Bacon, y demás.

Según Ernst Bloch existen dos tipos de utopías: las abstractas, que son la que nunca pueden llegar a realizarse, porque jamás se podrán dar las condiciones para ello; y, a diferencia de la anterior, las concretas. En el caso de estas últimas, tal vez en un momento no existan las posibilidades para su realización, pero en otras circunstancias sí pueden llevarse a cabo, como los submarinos o el viaje a la luna para Julio Verne, a diferencia de su proyectado viaje al centro de la tierra, aunque los seres humanos aún siguen intentándolo, como lo demostró el rescate de los mineros chilenos.

Las utopías abstractas más recientes han sido precisamente la del "capitalismo real" y la del "socialismo real". La primera propugnaba absolutizar el mercado en detrimento del Estado, la segunda promovió lo contrario, el predominio del Estado.

Ambas utopías parecen haber fracasado la primera desde la caída del Muro de Berlín, la segunda con la caída no menos estrepitosa de la bolsa de Wall Street.

En los días en que se presentó la primera versión del presente texto, se desarrollaba la campaña electoral en Estados Unidos de América, en la que el candidato demócrata Barak Obama respondía a los ataques de su opositor Mac Cain, argumentando que él no pretendía establecer el socialismo en ese poderoso país, sino buscar un punto algo más equilibrado para las mayorías o al menos para la clase media.

Parecía entonces que el candidato demócrata aspiraba también a realizar su utopía concreta, aunque ambos ignoraban que en Estados Unidos de América existen también otros grandes sectores sociales muy marginados que viven en condiciones realmente infra-animales, los cuales ni siquiera se mencionan en los discursos de las campañas electorales. Basta dar un paseo por el Central Park de New York para percatarse de ello.

También han habido formulaciones de utopías algo más concretas como la que plasmaron Marx y Engels en el Manifiesto Comunista o al menos han habido algunos experimentos sociales que se han planteado la tarea de aproximarse a ellas. 
La propuesta de Darío Botero de crear una comunidad política vitalista se inscribe en esa rica trayectoria del pensamiento que trata de transitar desde las utopías abstractas a alguna algo más concreta y son múltiples los momentos en su valiosa obra que así lo testifican, sin que en verdad haya podido escapar de las sutiles redes de las utopías abstractas.

Sus propuestas no han nacido de la mera especulación metafísica - no obstante que el autor conoce muy bien la trayectoria histórica de la mismapero no se atiene a ella, sino a la historia real de ensayos, unos más exitosos y otros fracasados, de construcción de sociedades más justas y equitativas, ya que las propiamente igualitarias ceden terreno a las utopías abstractas.

Entre las utopías abstractas se encuentran aquellas en las que se ha pretendido que el Estado por sí mismo ofrezca solución a todos los males sociales, en lugar que la sociedad misma junto al Estado genere instituciones y fórmulas que coadyuven en común a alcanzarlas. Inspirado en ese criterio Botero considera que: "la igualdad social como política estatal con el empleo de la fuerza del Estado es la castración de la vida social, el desestimulo a los más creativos. El esfuerzo político en favor de la igualdad social en el mundo de los distintos debe ser igualdad de acceso a la educación, favorecer la potenciación de todos los individuos para que puedan desarrollar sus aptitudes y talentos dentro de su disciplina y laboriosidad" (Botero, 2007, p. 369).

Ante la igualdad imposible, José Martí proponía la equidad posible. Un campesino michoacano en una ocasión me comentaba: "Aquí en México todos somos iguales, pero habemos algunos más iguales que otros". En aquellos momentos la Real Academia de la Lengua Española aún no nos había autorizado a emplear esa forma de conjugación: habemos. En la actualidad ya está autorizado, pero eso no significa que se haya modificado la situación en ese país así como en otros en cuanto a la desigualdad social.

En la obra en cuestión se destila un profundo análisis del por qué han fracasado los intentos de utopías abstractas y trata de buscar el punto medio que posibilite formular alternativas más reales y justas.

Esto se aprecia cuando sostiene que "La sociedad política que concibe el vitalismo cósmico es una sociedad abierta, democrática, en la cual la libertad juega un papel preponderante, pero no el libre juego de las fuerzas económicas, de la acumulación ilimitada generadora de miseria como ocurre en el capitalismo"(Botero, 2008, p. 43). Por supuesto que algo muy 
discutible es el asunto de si ha existido o no verdaderamente una sociedad de absoluto "libre mercado" o es también esta una utopía abstracta pensar que ha existido, existe o pueda existir el presunto "mercado libre", pues este siempre ha estado, y parece que estará, manipulado por fuerzas y mecanismos no muy libres que digamos.

El problema radica en que no se indica con claridad ¿cómo alcanzar ese tipo de comunidad? Le queda al lector una justificada nostalgia por encontrar alguna vía que no sea exclusivamente la del perfeccionismo ético para aproximarse a tal tipo de comunidad.

También se observa una valoración sobre algunas experiencias de lo que se ha dado en llamar países o sociedades comunistas, que podrían ser hoy, con razón, cuestionadas hasta por el propio Marx. Cuando plantea que no hay diferencia entre conservadores, liberales y comunistas al sostener que "Para los comunistas el orden después de la revolución representa lo logrado, deviene estático" (Botero, 2008, p. 32), por supuesto que es esta una generalización algo cuestionable, dadas las sustanciales diferencias que existen entre esas ideologías, con independencia del hecho de que alguno de sus seguidores en ocasiones realicen voltaretas de tal magnitud, que los sitúa en muchas ocasiones en las mismas posiciones que anteriormente habían criticado.

Por supuesto que todo depende también de lo que se entienda por comunismo. Si se entiende, como lo criticó el propio Marx, como un tipo de Estado absoluto a implantar, hay que coincidir con Botero, pero si es como el pensador de Tréveris inicialmente propugnó en La ideología alemana, donde sostenía que el comunismo debía ser un movimiento crítico de superación de un estado de cosas, para lo cual debía partir de las condiciones históricas realmente existentes, entonces habría que diferir al respecto.

Pero la historia no se valora tanto por lo que los filósofos han pensado, sino por lo que los pueblos y sus líderes, en un momento histórico, han conquistado, independientemente de sus consecuencias favorables o negativas. $Y$ parece que hay razones suficientes para seguir formulando utopías concretas, en la actualidad, como lo hacen políticos y pensadores que impulsan un tipo de socialismo del siglo XXI.

Otra cuestión es plantear qué se entiende por socialismo, pues si se reduce a considerar solamente la experiencia soviética, es posible llegar a la conclusión de que dicha alternativa al capitalismo esté congelado (Botero, 2008, p. 254) al identificarse el fracaso de algunos ensayos socialistas como 
la Unión Soviética y los países de Europa Oriental con toda posibilidad de socialismo y menos en estos tiempos actuales en América Latina en que ya no es precisamente un fantasma el que recorre el mundo.

El socialismo en América Latina se revela a través de algunas manifestaciones, tal vez no tan rojas como exigían ciertas interpretaciones presuntamente comunistas, pero sí con distintas tonalidades de rosados unos más fuertes y otros más débiles pero ante todo muy distintos, pero sí bien diferenciados de las azules.

El futuro de la humanidad parece que no será ni el socialismo real, ni el capitalismo real. Por lo que se puede coincidir con muchas de las críticas a esta última sociedad que se observan en esta obra de Botero en la que se plantea claramente su postura cuestionadora del carácter injusto de este último, cuando sostiene: "El capitalismo funda la desigualdad; su forma de acción no permite establecer un orden igualitario y justo [...] quien dice capitalismo dice desigualdad, despilfarro, destrucción" (Botero, 2008, p. 216). A la vez critica a la civilización occidental por su carácter ecocida, ya que considera que "No se puede continuar con la destrucción de los ecosistemas. En el capitalismo la destrucción es inevitable, porque la producción está jalonada por la ganancia” (Botero, 2008, p. 102). En otro momento con justificadas razones enfatiza "La empresa privada es responsable en gran medida del deterioro, pero no está en capacidad para corregirlo" (Botero, 2008, p. 255).

En todo momento se aprecia en Botero una abierta crítica al capitalismo en todas sus formas y en particular las que ha adoptado en los últimos años, pues a su juicio: "La llamada globalización es una recolonización: un colonialismo de nuevo tipo se instaura para regir las relaciones entre los países ricos y los pobres (...) la posmodernidad vitalista implicara el colapso de la globalización y el establecimiento de un nuevo orden económico. Un orden centrado en la vida es francamente incompatible con el capitalismo" (Botero, 2008, p. 217). Por tal motivo insiste en la necesidad de una filosofía de vida, pues sabe muy bien que el capitalismo propiamente no las asegura, por lo menos para la mayor parte de los países y población del mundo, sino para una elite oligárquica en los llamados países centrales o desarrollados y lógicamente para una aristocracia de menor magnitud en los periféricos o en "vías de desarrollo". Por tal motivo, con razón, Botero sostiene que: "El capitalismo solo ha logrado en algunas regiones influir 
desde fuera sin generar un autodesarrollo interno, o en todo caso desarrollando un desarrollo muy precario y dependiente. El capitalismo pese a la ampliación de su radio de acción sigue siendo un sistema de dominación de algunos estados poderosos" (Botero, 2008, p. 215).

De manera apropiadamente sintética Damián Pachon resume el pensamiento de Botero al plantear "Ese 'jardín de palabras' es una nueva filosofía desde América Latina que busca dar respuesta a lo que el autor llama 'la crisis de la modernidad tardía'; una filosofía que se presenta como alternativa a la crisis actual: crisis del sistema capitalista, crisis ambiental, muerte del arte, miseria material y espiritual y crisis del pensamiento occidental. Esta es la pretensión del filósofo quindiano" (Pachón, 2011, p. 254).

Botero críticamente considera que "El Estado en el siglo xx ha tenido un crecimiento sin precedentes. El movimiento neoliberal apunta efectivamente a detener dicho crecimiento y a organizar un Estado más pequeño. Pero toda su política está orientada solo desde el punto de vista de las empresas y de los capitales" (Botero, 1994, p. 133). Por lo tanto, no parece estar de acuerdo con que sea la vía del neoliberalismo la más apropiada para disminuir la fuerza del Leviatán.

En tanto que, según su criterio, "El centro del Estado moderno es el poder que orienta el capital” (Botero, 2008, p. 59). Botero intenta encontrar una fórmula armónica de solución a las contradicciones inherentes a la sociedad contemporánea; "Como vivimos hoy en la Edad del saber, - propone que- en la comunidad-política vitalista podemos invertir la relación y plantear el saber-poder" (Botero, 2008, p. 59).

Por otra parte su propuesta de la categoría de la no-razón (Botero, 2007, pp. 83-101), pretende superar la extrapolación de los límites del racionalismo que desde la filosofía moderna ha tratado de circunscribir la vida a una nueva forma de reduccionismo epistemológico (Guadarrama, 2007, pp. 83-101), que atenta contra una adecuada comprensión de la condición humana. Por tal razón, Botero considera que "El poder de Estado Capitalista es racional (ignora irracionalidad). El autogobierno por el contrario es racional-no-racional" (Botero, 2008, p. 64). De tal modo no está proponiendo una formula irracionalista, sino una en que las dimensiones axiológicas, éticas, estéticas, vitales del ser humano, se tengan en plena consideración.

El vitalismo cósmico de Botero se plantea una profunda reflexión antropológica cuestionadora, con razón, de una supuesta esencia humana dado su 
raigambre metafísico. En ocasiones pareciera identificarse más con la idea de una presunta naturaleza humana, aunque en otras ocasiones maneje el término de la condición humana, que tal vez pareciera el más apropiado para la valoración integral del ser humano, el cual se construye a sí mismo y no solo a través de la educación o la autoeducación, como a veces parece hiperbolizarse (Botero, 2008, p. 56) ${ }_{1}^{195}$ pues no solo la liberación de la ignorancia es condición de emancipación humana, son imprescindibles también múltiples transformaciones socioeconómicas, educativas ${ }^{196} \mathrm{y}$ culturales para que la misma encuentre mejores condiciones de producirse.

El vitalismo cósmico pretende ser una filosofía de la armonía social (Botero, 2007, p. 32), del mismo modo que otras tantas utopías han tratado de conseguirla. El problema ha consistido generalmente en cómo lograr esa armonía a partir de la existencia de individuos concretos, inmersos en sus contradicciones y desigualdades sociales, de género, generación, étnicas, entre otras.

La cuestión más controvertible en la propuesta de sociedad utópica que concibe Botero es cómo lograr las anheladas conquistas de armonía social que tiendan hacia la consolidación y salvaguarda de las comunidades de vida, si "El Estado es abolido; mi reflexión es precisamente que no se puede utilizar el Estado como instrumento para cambiar la sociedad; el Estado representa los viejos valores del uso del poder, de los privilegios, de la opresión, de la desigualdad" (Botero, 2007, p. 66).

Otra cuestión que resulta de difícil comprensión en Botero es mediante qué vías propone encontrar alguna solución a la actual situación de la sociedad, pues si según su criterio, "Ni el reformismo ni la revolución pueden cambiar la perspectiva histórica radicalmente" (Botero, 2007, p. 92). Por otra parte, considera "Las llamadas revoluciones fueron en la práctica involuciones políticas, no solo regresaron al siglo XvII, el absolutismo, sino

195 La primera versión de estas notas fueron presentadas en el homenaje a Darío Botero Uribe, que se efectúo en la Universidad Nacional de Colombia, atendiendo a la cordial invitación que me hizo de ofrecer una valoración de su libro.

196 "La política ha querido transformar al hombre a través de distintos mecanismos y siempre ha fracasado; el Vitalismo Cósmico aspira a cambiar al hombre cambiando la vida y mediante un procesos de educación y auto educación para la convivencia." Botero Uribe, D. La comunidad política vitalista, Corteza de Roble, Bogotá, 2008, p. 56. 
que no pudieron cambiar la vida ni en una millonésima" (Botero, 2007, p. 136). Tesis esta última muy cuestionable por cierto. ¿Entonces cuál es la tercera vía que pueda evadir exitosamente el reformismo y las propuestas revolucionarias?

Tal criterio suprime cualquier posibilidad de que el Estado pueda constituirse en un elemento favorable a la comunidad humana. Sin embargo, en otro momento, pareciera que Botero se percata de la necesaria función reguladora del Estado y favorable al mejoramiento social cuando sostiene que "habrá libertad de pensamiento, de expresión, de creación, de consciencia, pero no de libertad económica ilimitada, sino dentro de unos parámetros fijado por el Estado para defender los intereses sociales" (Botero, 2007, p. 44). De manera que, si por un lado aspira a la abolición del Estado, por otro le atribuye funciones de control y regulación muy favorables al mejoramiento social.

Tal vez nuestra capacidad racional no está aún suficientemente preparada para concebir la posibilidad de que existan gobernantes sin algún tipo de institución que los controle, fiscalice, incluso condene, cuando hemos visto que hasta en la actualidad los ejemplos sobran para demostrar que si no hubiera existido el Estado y no se hubiese perfeccionado y democratizado, sería el total desgobierno el que rigiera en el mundo contemporáneo.

Otra cuestión es que no haya conformidad con las funciones que ha desempeñado el Estado hasta la actualidad. Pero pretender eliminarlo a favor de una ilimitada libertad, puede conducir al mismo holocausto y genocidios que han propiciado algunos estados totalitarios.

Por supuesto que Botero se previene de no ser considerado un anarquista o un individualista, al considerar que "Cuando hablo de la formación de individuos no busco la anarquía ni una disolución social; por el contrario, postulo individuos sociales, que tienen consciencia de su lenguaje, de su cultura, de vínculos que los unen a grupos y a una comunidad política" (Botero, 2007, p. 212). En verdad su interés parece orientarse hacia una reconstrucción de la sociedad contemporánea en la que los individuos tengan un mayor margen de libertad, sin embargo, su insistencia en la abolición del trabajo y del Estado, estableciendo los mecanismos de autoresponsabilidad como el fundamental, lo hace aproximarse más a las posiciones del idealismo filosófico al respecto. 
Al menos lo anterior se puede inferir de las siguiente propuestas realizadas por él: "La libertad estará dada por cinco premisas: 1. La abolición del trabajo, que nos coloca en la sociedad del tiempo libre; 2. La ética Vitalista, que nos sitúa en el terreno de la autoresponsabilidad; 3. La abolición del Estado que deja a la sociedad como el orden organizativo, político y social autónoma (contradicción con tareas anteriormente asignadas al Estado); 4. El orden vitalista que implica el reordenamiento de la condición humana, de acuerdo con valores radicalmente nuevos; 5 . El orden basado en la vida" (Botero, 2007, pp. 256-257).

Esas ideas se reiteran en varias ocasiones en esta obra, especialmente su aspiración desalienadora de alcanzar una sociedad del tiempo libre. Así se expresa al plantear: "En la sociedad vitalista queda abolido el trabajo, como una forma opresiva, que humilla y empobrece al trabajador. Sera sustituido por formas distintas de actividad y de remuneración en las distinta formas de propiedad, del siguiente modo: actividad libre, labor solidaria y prestación de servicios: en la propiedad comunitaria se aplicara la actividad libre “(Botero, 2007, p. 82).

En ocasiones, su insistencia para que en el futuro humano predomine el reino de la libertad, hace recordar los acercamientos tempranos de Botero al marxismo en algún modo, pero a la vez su consideración de la abolición del trabajo al mismo tiempo lo distancia de él. Así se infiere cuando sostiene "El derrumbe del determinismo y la abolición del trabajo abren definitivamente el mundo a la libertad. Tendrá como todo alumbramiento dolor e incertidumbre. Sera un mundo a la medida del hombre, no ajeno sino propio" (Botero, 2007, p. 224).

En otro momento, considera que "En una cultura profunda de la vida, el dinero tiene que aparecer como necesario pero poco valioso; los valores creativos del talento, de la disciplina, de la realización humana deberán surgir con autonomía frente al dinero" (Botero, 2008, p. 239).

Indudablemente su aspiración a que se produzca una inversión de valores, los valores de la modernidad, hace inferir tanto la huella de Marx como de Nietzsche independientemente de las enormes distancias entre ambos pensadores (Guadarrama, 2005, pp. 47-90).

Enfrentándose a las diferentes formas de enajenación que genera el capitalismo, Botero considera que "La propiedad es el talento de los mediocres; 
el capitalismo permite que los mediocres tengan una compensación; la sensación de un yo que se infla con las cosas" (Botero, 2008, p. 240).

En el pensamiento general de Botero, y no solo del presente análisis, se aprecia una crítica abierta al individualismo y el utilitarismo que estimula esa sociedad, sin que esto implique algún tipo de disolución de la individualidad en la colectividad. Por el contrario, su preocupación por la dimensión social de la actividad humana y en especial de la vida política se asienta en la convicción de que es la única forma en que puede desplegarse convenientemente la individualidad humana.

En varias de las obras anteriores de Darío Botero se observa una extraordinaria valoración de la democracia (Botero, 2007, p. 368), ${ }^{197}$ que sin duda es una forma de Estado, por lo que no resulta muy consecuente su consideración respecto a la abolición del Estado.

En otro de sus análisis, anterior a este libro en cuestión, planteaba que "La democracia permite una mayor tolerancia con los pensadores, escritores y artistas creadores [...] la democracia es sin duda el régimen político que más criterio ilustrado exige del pueblo" (Botero, 1994, p. 147). Por supuesto que tal interacción dialéctica entre el pueblo y los sectores políticos, intelectuales, culturales, y otros, resulta muy cierta y necesaria, pues la experiencia histórica demuestra que los regímenes dictatoriales han proliferado en mayor medida en aquellos pueblos en los que los niveles de educación no han sido cultivados suficientemente.

A su juicio, "La democracia en mis perspectiva antes que un orden político es un orden social. Es un orden en el cual funciona fluidamente la ética, el poder de la palabra y el derecho. La democracia es un orden pacifico, justo, gratificante" (Botero, 2001, p. 163).

Para él, "Lo que permite la democracia es un cauce para ventilar las diferencias, la oposición. No simplemente para llegar al acuerdo" (Botero, 2001, p. 156). Precisamente el gran mérito de la democracia radica en la posibilidad de estimular el creativo disenso, ya que, a su juicio: "Desde el punto de vista de la articulación de razón y no-razón-, en mi perspectiva un acuerdo general y permanente de la sociedad seria la esclerosis y

197 "La democracia en tanto concepción de la vida es la teoría propia del Vitalismo Cósmico." Botero Uribe, D. Vitalismo cósmico, Editorial Corteza de Roble, Bogotá, 2007, p. 368. 
la muerte. El desacuerdo es creador, fecundo. Se dialoga entre otras razones para evitar que el desacuerdo derive violencia. Se puede vivir en desacuerdo con muchos sectores y, por supuesto, con los sectores dominantes" (Botero, 2001, p. 157).

Botero se lamenta de que "El pueblo es un invitado a la mesa redonda de la democracia, pero un invitado ausente, un invitado que solo hace presencia muy pocas veces, y aun así todo el mundo confía en su sabiduría y en su buen juicio." (Botero, 1994a, p. 116). A partir de la consideración de tal ausencia o carencia de protagonismo en el desarrollo social, propone que "[...] una innovación política debe sustituir el concepto pueblo por un concepto dinámico capaz de transformar una democracia formal en una democracia real. El concepto sustitutivo que propongo es el de comunidades de vida." (Botero, 2008, p. 53). Resulta algo difícil de comprender las características y exigencias de tales comunidades de vida, pues no están debidamente definidas en el libro en cuanto a su contenido real. De ahí que se haga más difícil justipreciar el posible aporte teórico y la posible utilidad práctica de la implementación de las mismas.

Acertadamente enfatiza que "La democracia en cuanto se basa en hombres libres debe luchar contra la alienación, tiene que tratar de reconstruir hombres realizados, hombres que pueda reconocerse en el producto de su trabajo, en la creación, en la personalidad e incluso en la pertenencia y unidad de su corporoespiritualidad" (Botero, 1994, p. 153).

De otro modo no podría comprenderse plenamente el humanismo propugnado por Botero a través de sus libros, como Discurso sobre el humanismo y su praxis pedagógico-educativa; "El vital humanismo se ocupa de defender la vida biológica (la vida en sentido universal comprendida la vida humana) y de la potenciación (conatus) de la vida sicosocial; en otras palabras, la defensa de los ecosistemas, del aire, el agua, los bosques; o de otra manera, la búsqueda de una naturaleza vigoroza y sana; pero, de otro lado, la dignidad de la vida, los derechos humanos, la educación y el bienestar" (Botero, 2004, p. 213). De tal manera que su propuesta humanista no parte de presupuestos antropocéntricos, sino que aspira a una perspectiva ecosistémica y transnaturalizada, aun cuando en ella el hombre kantianamente mantenga su teleológico estatus.

Por tal razón, resulta algo contraproducente que haya considerado que "En la nueva perspectiva de la historia, la crítica humanista de Nietzsche está 
plena de sentido." (Botero, 2002, p. 132). Tal vez la postura vitalista de Botero le haya propiciado ese acercamiento al gran pensador alemán.

Del mismo modo presupone una consideración sobre el papel del trabajo, el ocio y la libertad. Limitar el trabajo a una visión unilateral en la que se enfatice su posible y real aspecto alienante en determinadas condiciones históricas; "Solo habrá democracia — plantea - cuando el acceso a la propiedad alcance a una parte considerable de los campesinos (...) en la comunidad vitalista no habrá propiedad privada del campo. Solamente coexistirán propiedad social, comunitaria e individual" (Botero, 2008, p. 119).

Propone que "El Vitalismo Cósmico no postula la abolición de la propiedad sino más bien le da una orientación nueva" (Botero, 2008, p. 127). Y una vez más reitera que "En la comunidad política-vitalista la propiedad no será una dictadura sobre el trabajo. El trabajo será abolido y sustituido por actividad libre, labor solidaria y prestación de servicios” (Botero, 2008, p. 129).

Algo que llama la atención en la propuesta de la comunidad política es el cuestionamiento del papel del pueblo como sujeto de la transformación social (Botero, 2008, p. 96).

Es evidente que con este concepto se han hecho manipulaciones extraordinarias y en nombre del "espíritu del pueblo" (Volkgeist) se han desarrollado las políticas más totalitarias y antipopulares. Pero la historia demuestra que donde más eficiente ha sido la acción histórica de los sectores mayoritarios de la población es cuando se ha unido en función de objetivos comunes los sectores sociales más homogéneos. Y sólo en la unidad y no en la atomización de las comunidades vitalistas aisladas.

No resulta difícil coincidir con Botero en cuanto a la crítica a la democracia formal y la búsqueda de una democracia real (Botero, 2008, p. 53), pero dudamos de la eficacia de una democracia directa por los peligros de populismo tanto de izquierda como de derecha que puede traer aparejado.

Muchas son nuestras coincidencias con el pensador colombiano sobre la necesaria diferenciación entre globalización y mundialización (Guadarrama, 2006), así como sobre el diferente impacto de la misma para los países desarrollados y los más atrasados, pero de ahí a pensar que por simple voluntad política se pueda prescindir de la globalización y de sus efectos positivos y negativos va un significativo trecho. Resulta mucho más objetivo y provechoso estudiarla en todas sus implicaciones y proponer actitudes y políticas acertadas ante ella. 
Otro tema indiscutiblemente debatible es el de que "La modernidad está agotada" (Botero, 2008, p. 254), ante el auge a fines del pasado siglo del discurso postmodernista. En el caso de América Latina y otras regiones periféricas de los países capitalistas centrales, no hay dudas de que la supuesta plenitud de la modernidad debe ser cuestionada por su carácter verdaderamente malogrado (Guadarrama, 1988, pp. 13-18) ${ }^{198}$ y no tanto incumplido o no realizado. Tal vez resulta mejor plantear nuevos conceptos como el de transmodernidad planteado por Enrique Dussel (1999) y buscar alternativas diacrónicas y no sincrónicas sobre el devenir de la historia a fin de sugerir mejores actitudes que superen los extremos del nihilismo, o del infundado progresismo ilustrado o positivista en aras de construcción de filosofías más realistas en cuanto a sus objetivos y posibilidades de verse realizadas en la práctica social.

Por otro lado, resulta necesario a la filosofía poseer un definido concepto de cultura (Guadarrama, 2009c. p. 141) ${ }^{199}$ que evite el contrasentido, al menos en su sentido etimológico, de conceptos considerados por Botero

198 "Pensar que la historia de la entrada de nuestra América a los tiempos modernos puede medirse temporalmente con el tiempo específico que reclama para todo sistema la teoría de la relatividad, puede resultar un ejercicio, más que fisicalista, pernicioso. Es imposible desarticular la modernidad europea del proceso expansivo y colonizador sobre estas y otras tierras del orbe, que simplemente participaron del show de la modernidad, pero desde la calle. Sin poder disfrutar de los deleites del buffet. Eso no significa de ningún modo que el acontecimiento no tuviera lugar, sólo sucedió que las invitaciones eran tan limitadas que incluso muchos inquilinos del centro, varios de los cuales son ahora víctimas de la xenofobia, tuvieron que compartir con sus vecinos periféricos la nostalgia. América Latina, por otra parte, no puede seguir esperando que algún día el show se repita para disfrutarlo en toda su plenitud. Porque esa posibilidad no se ofrecerá jamás. Tampoco parece recomendable saltar de lleno hacia la postmodernidad, teniendo pendiente tantas deudas con la modernidad". Guadarrama, P. "La malograda modernidad latinoamericana" en América Latina, marxismo y postmodernidad. Universidad INCCA de Colombia. Bogotá. 1994 p. 65-76; Humanismo, marxismo y postmodernidad. Editorial Ciencias Sociales. La Habana. 1998. p. 134-143; Exégesis. San Juan de Puerto Rico. Año 7. 20. 1994. p. 13-18.

199 "Una posible definición integradora debe considerarla como el grado de dominación por el hombre de las condiciones de vida de su ser, de su modo histórico concreto de existencia, lo cual implica de igual modo el control sobre su conciencia y toda su actividad espiritual, posibilitándole mayor grado de libertad y beneficio a su comunidad". Guadarrama, P. "Cultura". Diccionario del pensamiento alternativo. Hugo E. Biagini y Arturo A. Roig (directores). UBA. Buenos Aires, 2009. p. 141. 
como "cultura de la violencia", (Botero, 2008, p. 262) que al parecer son expresiones de contracultura, que en verdad constituyen excrecencias sociales que la sociedad debe purgar.

Muy acertado es el criterio de Botero sobre el futuro y el papel de la filosofía contra los augurios apocalípticos del positivismo (Botero, 2008, p. 253). La filosofía ha servido siempre y servirá, como lo demuestran hoy los tanques pensantes, como un valioso instrumento de transformación práctica con sus aportes teóricos.

Aunque por lo comúnmente aceptado no significa que necesariamente sea sólido el criterio según el cual el discurso filosófico nació en Grecia (Botero, 2008, p. 221), ${ }^{200}$ ignorando su existencia en el mundo oriental, como Diógenes Laercio reconoció, pero el problema no es de simple carácter de disputa académica, es de mayor envergadura por su dimensión ideológica actual que implica desconocer la producción filosófica latinoamericana incluso contemporánea y otorgarnos sólo la condición de hermeneutas o exegetas de filósofos europeos o norteamericanos. Por lo que el propio vitalismo cósmico así como otras producciones intelectuales latinoamericanas o de autores como Bello, Vasconcelos, Zea, Dussel, Bunge, Roig, entre otros, deberían ser excluidos de la historia universal de la filosofía.

En fin, múltiples podrían ser las objeciones o diferencias que se podrían argumentar respecto a algunas de las propuestas de Darío Botero y en particular respecto a experiencias del mundo realmente existente. Ahora bien, se debe, académicamente por un lado, pero especialmente por razones humanistas y desalienadoras, valorar el esfuerzo de Darío Botero por constituir esa comunidad vitalista. Sobre todo es muy estimable su intención por recuperar esa dimensión de la filosofía al centrar su atención en la vida que desde Dilthey, Nietzsche o Bergson alcanzó una significación espiritual integral que no había encontrado en el reduccionismo biologicista de Comte, Spencer y otras expresiones del positivismo y el materialismo científico natural decimonónico.

Por último, algunas reflexiones sobre las consideraciones de Botero en relación con el marxismo. En una obra anterior enfatizó que "El marxismo

200 "Para nosotros infortunadamente sería menor la participación de la filosofía. Al fin y al cabo, fueron los griegos los creadores del discurso filosófico." Botero Uribe, D. La comunidad política vitalista, Corteza de Roble, Bogotá, 2008, p. 221. 
es también una 'antropología' filosófica, una teoría de la libertad, y de la justicia social, de la objetivación de la esencia humana, es decir, una cosmovisión que prevé la realización de la razón filosófica más alta en una sociedad desalienada, igualitaria y libre de todas las formas conocidas de explotación y de opresión" (Botero, 1996, p. 328).

A la vez consideraba, no sin faltarle razón que "el marxismo occidental, a mi juicio la corriente más brillante del pensamiento contemporáneo, el marxismo-leninismo de estirpe soviética [...] una de las formas más atrasadas del pensamiento actual por su simplismo, dogmatismo, economicismo, esquematismo y mecanicismo." (Botero, 1996, p. 329).

Y por eso llegaba a la conclusión de que "La razón fundamental por la cual la teoría marxista no tiene que ver con el socialismo real es que la prognosis de Marx en torno al socialismo, como forma de transición del capitalismo avanzado a la sociedad sin clases no se ha realizado praxiológicamente en el proceso histórico" (Botero, 1996, p. 331).

No cabe dudas que las experiencias del llamado "socialismo real" no deben ser consideradas como desarrolladas en correspondencia fidedigna con las ideas de Marx, pero tampoco debe considerse que no tuvieron nada que ver con este pensador. Algo similar debe pensarse en cuanto a la relación de la filosofía de Nietzsche con el nazismo (Guadarrama, 2005, p. 47-90), por supuesto que no se le puede atribuir a este última la culpabilidad ideológica con el desarrollo del inhumano totalitarismo que caracterizó a este régimen, pero tampoco se debe desconocer la influencia que tuvo su vitalismo nihilista en la ideología propugnada por Hitler.

En el producción filosófica latinoamericana han sido realmente pocos los que desde puntos de partida personalistas, vitalistas o existencialistas han acentuado la significación holística y práctica que debe tener la vida para la comprensión del lugar del ser humano en el cosmos y su dinámica interacción entre ambos. Este es, a nuestro juicio, uno de los mayores méritos del pensamiento filosófico de Dario Botero. Pero tal vez por encima de todo esté su intención de que no quede en formulaciones abstractas o simple declaratoria de buenas intenciones, sino convertir su filosofía en instrumento orientador de transformación socioeconómica y política, "El sol tiene manchas, los desagradecidos solo ven las manchas" planteaba José Martí, "los agradecidos solamente aprecian la luz". 
Se podrá estar a favor o en contra del vitalismo cósmico de Darío Botero y en particular con su propuesta de crear una comunidad política vitalista, pero lo que resulta imposible es ignorar su lugar dentro de la producción filosófica colombiana y latinoamericana contemporánea, su aportativa función en la crítica reflexión sobre la sociedad contemporánea y su contribución para superarla por una más humanizada, desalienada y, por tanto, más libre. 



\section{Epílogo}

Los filósofos más auténticos, en todas las épocas y circunstancias, cuando han reflexionado sobre los temas más abstractos, aparentemente han estado desvinculados de la realidad en que han vivido. Pero en verdad ha sido todo lo contrario, pues lo han hecho tomando en debida consideración las condiciones socioeconómicas, políticas y culturales en que han engendrado y cultivado sus propias ideas. Nunca han sido importadores acríticos de ideas engendradas en otros contextos culturales. Los pensadores latinoamericanos, y en particular los colombianos, en modo alguno han constituido una excepción al respecto.

Todos ellos han sabido nutrirse debidamente de aquellos instrumentos epistemológicos, metodológicos, axiológicos, y otros, que le han aportado las generaciones anteriores y coetáneas de pensadores que en otras latitudes se han preocupado sobre múltiples temas, que al constituir intentos de respuestas a múltiples interrogantes que se han planteado los seres humanos en sus correspondientes circunstancias, en la misma medida en 
que lo han logrado, han ido a enriquecer el infinito tesoro del saber filosófico universal. ${ }^{201}$

De tal forma, ideas engendradas en contextos socioculturales muy disímiles han servido y continuarán sirviendo para que hombres y mujeres de latitudes y épocas muy distantes puedan aprovecharlas, enriquecerlas y reincorporarlas al acervo filosófico de la humanidad. Otra cuestión es que por los medios de difusión no siempre han encontrado estas ideas las vías más apropiadas para una recíproca interacción con otros pueblos. Precisamente, los investigadores del desarrollo del pensamiento filosófico latinoamericano tenemos el deber de utilizar todas las extraordinarias posibilidades que nos conceden las nuevas tecnologías de la información y la comunicación, para divulgar las aportantes reflexiones de aquellos pensadores latinoamericanos que no contaron con el actual aparato divulgativo.

Los pensadores latinoamericanos que han sabido rastrear de manera debida las huellas de filósofos de otras épocas y contextos — sin desembocar en simples mimetismos que les convirtiese en dóciles y fieles reproductores de sus ideas-, se han apropiado de sustanciosas propuestas de análisis en la misma forma que le han incorporado la perspectiva del prisma propio y, en tal sentido, han sabido dejar sus propias huellas, que en la actualidad tenemos el deber investigar, retomar, repensar y proyectar con luz e instrumentos epistémicos propios sobre nuestras actuales circunstancias. De otro modo convertiríamos a la historia de la filosofía universal y su expresión particular latinoamericana en un estéril museo de cera en el que las figuras tratan

201 "La filosofía latinoamericana ha sido auténtica en tanto ha coincidido con la línea ascendente de la filosofía universal, que en el caso del pensamiento de la modernidad llega el momento en que la burguesía desempeñó un papel progresista, momento este en que no coinciden la historia de este continente y la historia universal, razón por la cual se observan filosofías como el positivismo, que ya universalmente marcaban el inicio de la decadencia de la filosofía moderna y aún desempeñarían una función progresista por regla general en América Latina dadas sus condiciones específicas de atraso socio-económico. La autenticidad de la filosofía latinoamericana se demuestra al constatarse su coincidencia con las exigencias del desarrollo histórico en cada período, por eso ha sido o auténtica y lo será cada vez más en la misma medida en que se corresponda con sus circunstancias presentes e históricas" Guadarrama, P. Pensamiento Filosófico Latinoamericano. Humanismo, método e historia. Universitá degli Studi di Salerno-Universidad Católica de Colombia-Planeta. Bogotá. Tomo I. 2012. p. 99. 
de parecerse exteriormente al máximo a las personalidades que representan, pero que jamás podrán lograr la vitalidad que los caracterizó.

Estudios cada vez más amplios y profundos, nutridos de fuentes archivísticas y otros medios, cada día revelan nuevos ejemplos de múltiples interacciones transculturales entre el pensamiento filosófico latinoamericano con los de otras regiones del orbe, desde el mismo proceso de colonización a través de sus diversas formas de desarrollo desde la escolástica, la ilustración, el inicio de la época de vida política independiente de los países de la región hasta el presente.

Por supuesto que un simple rastreo de estas recíprocas apropiaciones y enriquecimientos se pueden apreciar mucho mejor desde fines del siglo XIX y de forma impresionante desde la aparición de Internet.

La descomunal apertura de las redes comunicativas desde fines del siglo xx hasta la actualidad no justifica que ningún pensador permanezca enclaustrado, a menos que sea su expresa voluntad.

Ancestrales inquietudes sobre el objeto y la función de la filosofía se reviven y reaparecerán siempre porque constituyen ejes imprescindibles de inflexión dubitativa y tema de controversia permanente. De ahí que se debe tener satisfacción porque así sea, pues el acomodamiento intelectual jamás ha promovido ni promoverá aportes teóricos de valor a las emergentes generaciones de filósofos.

Que algunos pensadores latinoamericanos, al igual que los de otras épocas y pueblos, no hayan dedicado atención particular al tema sobre el objeto y la función de la filosofía en respuesta a la preguntas sobre ¿por qué? y ¿para qué filosofar?, no debe significar que de algún modo no haya estado presente en sus respectivas producciones teóricas. Siempre, de alguna manera, estas preocupaciones aflorarían en la diversidad de sus reflexiones filosóficas y bastará una esmerada investigación para descubrirlas.

Algo similar ha ocurrido con la cuestión de la funcional interrelación epistemológica e ideológica entre filosofía, ética y política. Tal vez de una forma precisa, bajo esos términos, no sea tarea fácil encontrar análisis sobre el tema, pero basta desbrozar un poco la frondosa maleza de sus ideas para que esta cuestión aflore encubierta a través de otras preocupaciones.

Basta detenerse en algunos de los autores colombianos que se analizaron en el presente libro para percatarse de que en verdad está latente en diverso grado en cada uno de ellos. 
Si se admitiese hipotéticamente que algún cultivador latinoamericano de la filosofía tratase obstinadamente de sostener una exquisita presunta neutralidad axiológica en relación con la funcional interrelación epistemológica e ideológica entre filosofía, ética y política, bien se podría decir que ese sería el momento de aceptar la certificación de defunción de la filosofía.

Los autores colombianos que se estudiaron en el presente libro tuvieron relaciones muy diferentes respecto a la filosofía. Sin embargo, todos ellos hicieron de la filosofía un instrumento epistémico de extraordinario valor. Algunos podrían con criterios esquemáticos de lo que es un filósofo, cuestionarse su condición de poseer tal calificativo. Ahora bien, lo importante no es tanto si sus nombres deben estar o no en una selecta galería de filósofos. Lo que los hace meritorios de ser objeto de análisis en el presente estudio sobre las huellas del filosofar en Latinoamérica es que todos ellos hicieron de la filosofía un valioso e indispensable instrumento de análisis para tratar de comprender y sobre todo transformar sus respectivas circunstancias $\mathrm{y}$ aportaron ideas de valor que hoy deben ser tomadas en digna consideración porque trascienden a sus épocas. Esto ya es motivo suficiente para que tales ideas estén disponibles en el instrumental epistemológico, axiológico y práctico para la misma labor que hoy nos corresponde y que necesariamente deben asumir las nuevas generaciones. 


\section{Referencias bibliográficas}

Abbagnano, N. (1966). Diccionario de filosofía. La Habana, Cuba: Edición Revolucionaria.

Abbagnano, N. (1967). Historia de la filosofía. La Habana, Cuba: Editorial Estudios. T. I.

Aguilar, A. (1953). Conversaciones filosóficas interamericanas. La Habana, Cuba: Ministerio de Educación.

Alberdi, J.B. (1986). “Ideas para un curso de filosofía contemporánea”. En Ideas en torno de Latinoamérica._México: UNAM.

Althusser, L. (1969). "Lenin y la filosofía". Pensamiento crítico, 34-35.

Althusser, L. (1977). "Ideología y aparatos ideológicos del Estado”. En Posiciones. Barcelona, España: Anagrama.

Althusser, L. (1966). Por Marx. La Habana, Cuba: Ediciones. Revolucionaria.

Althusser, L. y otros. (1968). Polémica sobre marxismo y humanismo. México: Siglo XXI.

Alvargonzález, D. (1996). "El darwinismo visto desde el punto de vista filosófico". En El Basilisco, enero-marzo. 
Álvarez, J, (2012). Aportes para una filosofía del Sujeto, el Derecho y el Poder. Bogotá, Colombia: Universidad Libre de Colombia.

Anderson, P. (1985). Consideraciones sobre el marxismo occidental. México: Siglo XXI.

Aquino, T. de. (1975). Suma teológica. En Torres, E. Antología del pensamiento medieval. La Habana, Cuba: Editorial Ciencias Sociales.

Ardiles, O. (1988). El exilio de la razón. Córdoba, Argentina: Sils-María.

Aristóteles. (1964). Gran ética. Madrid, España: Aguilar.

Aristóteles. (1968). Metafísica. Política. La Habana, Cuba: Editorial Estudios.

Bacon, F. (1963). Nuevo Órgano. En Marías. J. La filosofía en sus textos. Barcelona, España: Editorial Labor.

Bagú, S. (julio de 1988). "Valor interpretativo de la obra de Marx y Engels aplicable a la realidad de América Latina”. Dialéctica, 19.

Baltodano V. . (1981). Los pensamientos básicos del materialismo histórico y su desarrollo en el Perú. Trujillo, Perú: Editorial Universitaria,

Bello, A. (1948). Filosofía del entendimiento humano. México: Fondo del Cultura Económica.

Berdiaeff, N. (1947). Il destino dell' uomo nel mondo contemporaneo. Bombiani. (s.e).

Bermúdez, E. (1998). La dialéctica en Luis Eduardo Nieto Arteta. Barranquilla, Colombia: Ed. Centro Russell.

Beorlegui, C. (2004). Historia del pensamiento filosófico latinoamericano. Bilbao: Universidad de Deusto.

Biagini, H. y Roig, A. (2009). (Dir). Diccionario de pensamiento alternativo. Buenos Aires, Argentina: Biblos.

Bloch, E. (1974). El hombre y el ciudadano según Marx. En (vol. colec.). Humanismo socialista. Buenos Aires, Argentina: Ed. Paidos.

Bobbio, N. (1988). Las ideologías y el poder en crisis. Barcelona, España: Ariel.

Bobbio, N (2001). Ni con Marx, ni contra Marx. Ciudad de México, México: Fondo de Cultura Económica.

Bolívar, S. (1947). Obras completas. La Habana, Cuba: Editorial Lex.

Borda, F. Molina, G. Fajardo, D. y otros. (1983). El marxismo en Colombia. (s.d.). Bogotá: Universidad Nacional de Colombia,

Botero, D. (1991). "De la unidimensionalidad racional a la pluridimensionalidad humana". Revista Politeia, 7. 
Botero, D. (1994). El derecho de la utopía. Bogotá, Colombia: ECOE Ediciones.

Botero, D. (1994a). "Pensar la democracia”. En Collazos, O. Guerrero, A. García, S. y otros. Arte y cultura democrática. Bogotá, Colombia: Instituto para el Desarrollo de la Democracia Luis Carlos Galán.

Botero, D. (1996). El poder de la filosofía y la filosofía del poder. Bogotá, Colombia: Universidad Nacional de Colombia.

Botero, D. (2001). Teoría social del derecho. Bogotá, Colombia: Universidad Nacional de Colombia, tercera edición

Botero, D. (2002). La voluntad de poder de Nietzsche. Bogotá, Colombia: Universidad Nacional,

Botero, D. (2004). Discurso sobre el humanismo. Bogotá, Colombia: ECOE Ediciones.

Botero, D. (2007). Vitalismo cósmico. Bogotá, Colombia: Editorial Corteza de Roble.

Botero, D. (2008). La comunidad política vitalista. Bogotá, Colombia: Corteza de Roble.

Brehier, E. (1962). Historia de la filosofía. Buenos Aires, Argentina: Editorial Sudamericana. $\mathrm{T}$.

Broccoli, A. (1978). Ideología y educación. México: Edit. Nueva Imagen.

Buenaventura, S. (1975). "Reducción de las ciencias a la teología”. En. Torres, E. Antología del pensamiento medieval. La Habana, Cuba: Editorial Ciencias Sociales.

Bueno, G. (1995). ¿Qué es la filosofía? Oviedo: Pentalfa.

Bueno, G. Hidalgo, A. y Iglesias, C. (1987). Symploke. Barcelona, España: Ediciones Júcar.

Buhr, M. (1970). (Coord). Philosophisches Wörterbuch . Leipzig, Deutschland: VEB Bibliograhisches Institut.

Bunge, M. (1985). Seudociencia e ideología. Madrid, España: Alianza Universidad.

Bushnell, D. (1998). El siglo IX argentino en perspectiva continental: las "homologías colombo-argentinas" de Nieto Arteta, reexaminadas. Buenos Aires, Argentina: Academia Nacional de Historia.

Caicedo, H. (1987). “Antonio García, un caminante y un camino”. En García, A. Dialéctica de la democracia. Bogotá, Colombia: Plaza y Janes.

Caro, T. L. (1968). De la naturaleza de las cosas. Madrid, España. (s.e.).

Carpentier. A. p. (2007). Problemática de la actual novela latinoamericana. En Carpentier, A. Los pasos recobrados. La Habana, Cuba: Ediciones Unión. 
Carrillo, R. (1986). Escritos filosóficos. Bogotá, Colombia: Universidad Santo Tomás.

Castro, M. (1953). Conversaciones filosóficas interamericanas. La Habana, Cuba: Sociedad Cubana de Filosofía.

Cataño, G. (1983). “Luis E. Nieto Arteta: marxismo y participación política”. En El marxismo en Colombia. Bogotá, Colombia: Universidad Nacional, Facultad de Ciencias Humanas.

Cataño, G. (2013). La introducción del pensamiento moderno en Colombia. El caso de Luis E. Nieto Arteta. Bogotá, Colombia: Universidad Externado de Colombia.

Cerutti, H. (1983). Filosofía de la liberación latinoamericana. México. Fondo de Cultura Económica.

Cerutti, H. (1986). Humanismo del hombre de carne y hueso en la filosofía de la historia americana. Prometeo, 7. Guadalajara (septiembre-diciembre).

Colectivo de autores. (1981). Marxismus und Spinozismus. Seidel, H. (Coord.). Karl Marx Universität, Leipzig.

Colectivo de autores. (1986). Diccionario de filosofía con autores y temas latinoamericanos. Bogotá, Colombia: Editorial El Búho.

Comte, A. (1973). Sistema de política positiva. En Lecturas sobre historia de la filosofía. La Habana, Cuba: Universidad de La Habana.

Conversaciones filosóficas interamericanas. (1953). La Habana, Cuba: Publicaciones de la Sociedad cultural de Filosofía.

Cortina, A. (2007). Ética de la razón cordial. Educar en la ciudadanía en el siglo XXI. Oviedo: Ediciones Nobel.

Cruz, Vélez, D. (1989). El mito del rey filósofo. Bogotá, Colombia: Planeta Colombiana Editorial.

Descartes, R. (1971). “Los principios de la filosofía”. En_Obras de Renato Descartes. La Habana, Cuba: Editorial Ciencias Sociales.

Díaz de Gamarra, B. (1963). Elementos de filosofía moderna. México: UNAM.

Diogenes Laercio- Filostrato. (1990). Vida de los filósofos más ilustres. Vida de los sofistas. (s.d.). Editorial Ciencias Sociales.

Dion, M. (1975). Soziologie und Ideologie. Akademie Verlag Berlin .

Djilas, M. (1970). La sociedad imperfecta. Barcelona, España: Ariel.

Domínguez, D. (1953). Conversaciones filosóficas interamericanas. La Habana, Cuba: (s.e.). 
Dussel, E. (1973). Para una ética de la liberación latinoamericana. Buenos Aires, Argentina: Editorial Siglo XXI.

Dussel, E. (1973). Filosofía latinoamericana y método analítico en Latinoamérica. Anuario de Estudios Latinoamericanos, 6.

Dussel, E. (1983). Praxis latinoamericana y filosofía de la liberación. Bogotá, Colombia: Editorial Nueva América.

Dussel, E. (1985). La filosofía de la liberación. Buenos Aires, Argentina: Ediciones La Aurora.

Dussel, E. (1988a). Introducción a la filosofía de la liberación. Bogotá, Colombia: Editorial Nueva América.

Dussel, E. (1988b). Hacia un Marx desconocido. Un comentario de los manuscritos del 61-63. Iztapalapa: Siglo XXI.

Dussel, E. (1989). Retos actuales de la filosofía de la liberación. Libertacao, 1 (1).

Dussel, E. (1999). Posmodernidad y transmodernidad. Diálogos con la filosofía de Gianni Vattimo. México: UAM.

Dussel, E. (2001). Hacia una filosofía política crítica. Bilbao: Editorial Desclée de Brouwer, S.A.

Dussel, E. Mendieta, C y C. Bohorquez. (2009). El pensamiento filosófico latinoamericano, del Caribe y "latino" (Siglo XIV-Siglo XX). México, Buenos Aires, Madrid: CREAL, Siglo XXI.

Eastman, J.M. (1979). “Presentación” a Nieto Arteta, Luis Eduardo. En Obras selectas. Bogotá, Colombia: Imprenta Nacional.

Eastman, J. M. (2000). Trece pensadores del Liberalismo social. Bogotá, Colombia: Dirección Liberar Nacional.

Rabossi, E. (1984). "Enseñar filosofía y aprender a filosofar”. Cuadernos de Filosofía y Letras, 3-4.

Engels, F. (1961). Dialéctica de la naturaleza. México: Editorial Grijalbo.

Engels, F. (1965). Anti-Dühring. La Habana, Cuba: Editora Política.

Engels, F. (1967). “Introducción a K. Marx, La lucha de clases en la Francia de 1848 a 1859”. En Marx, K. Engels, F. Las guerras campesinas en Alemania. La Habana, Cuba: Editora Política.

Engels, F. (1972). “Ludwig Feuerbach y el fin de la filosofia clásica alemana”. En Marx, K, y F. Engels. Obras Escogidas. Moscú, Rusia: Editorial Progreso. 
Engels, F. (1976). “Contribución a la crítica del proyecto de programa socialdemócrata de 1891”. En Marx, K. Engels, F. Obras Escogidas. Moscú, Rusia: Ed. Progreso.

Fabelo, J.R. (1993). “Epílogo”. En Risieri Frondizi. Pensamiento axiológico. (Antología). Cali, Colombia: Instituto Cubano del Libro-Universidad .

Feuerbach, L. (1985). Tesis provisionales para la reforma de la filosofía. En Dominic. E. y otros. Antologías de la Filosofía Clásica Alemana. La Habana, Cuba: Universidad de La Habana.

Fukuyama, F. (1993). El fin de la historia y el último hombre. Bogotá, Colombia: Editorial Planeta.

Gaitán, J. E. (1946). Sus mejores discursos. (Conferencia Teatro Municipal). Bogotá, Colombia, abril 20.

Gaitán, J. E. (1953). Obra científica. (Vol. IV) . Bogotá, Colombia: Edición Ministerio de Educación Nacional.

Gaitán. J.E. (1968). Antología de su pensamiento económico y social. Bogotá, Colombia: Ediciones Suramericana.

Gaitán, J. E. (1979). Manifiesto Unirismo. Obras selectas. (T. V) . Bogotá, Colombia: Parte Primera, Cámara de Representantes, Imp. Nacional.

Gaitán J. E. (1985). Escritos políticos. Bogotá, Colombia: El Ancora Editores.

Gaitán, J. E. (1998). La plataforma del Colón. Bases políticas para el cambio económico. En Valencia, L. E. El pensamiento económico en Jorge Eliécer Gaitán. Bogotá, Colombia: Universidad Nacional de Colombia.

Gallardo, H. (1989). Elementos de política en América Latina. Costa Rica: Editorial DEI.

García, A. (1987). Dialéctica de la democracia. Bogotá, Colombia: Plaza Janes Editores.

García Galló, G. (s.f.). El humanismo martiano. En Simposio Internacional Pensamiento Político y Antimperialismo. Memorias. La Habana, Cuba: Editorial Ciencias Sociales.

García Bárcena, R. (1949). Coyuntura histórica para la filosofía latinoamericana. Revista Cubana de Filosofía, 1.

García, A. (1952). El cristianismo en la teoría y la práctica. Bogotá, Colombia: Fondo de Publicaciones Vicente Azuero.

García, A. (1953). El comunismo y la contrarrevolución en Colombia. En García, A. La rebelión de los pueblos débiles. Bogotá, Colombia: Fondo Socialista de Publicaciones Tomás Uribe Márquez. 
García, A. (1955). Gaitán y el problema de la revolución colombiana. Bogotá, Colombia: Cooperativa Colombiana de Editores.

García, A. (1972). Atraso y dependencia en América Latina. Buenos Aires, Argentina: Editorial El Ateneo.

García, A. (1972a). Interpretación de la ciencia colombiana y latinoamericana. En Manuscrito inédito, 21. Bogotá, Colombia: Círculo de Estudios Económico Sociales Antonio García.

García, A. (1977). Una vía socialista para Colombia. Bogotá, Colombia: Ediciones Cruz del Sur Ltad.

García, A. (1978). La estructura del atraso en América Latina. Hacia teoría latinoamericana del desarrollo. Buenos Aires, Argentina: El Ateneo, Pedro Garcia. S.A.

García, A. (1987). Dialéctica de la democracia. Colombia: Editorial Plaza \&Janes.

García, A. (1988). Planificación municipal. Bogotá, Colombia: Universidad Distrital Francisco José de Caldas.

García, A. (1995). De la rebelión a la organización de los pueblos débiles. Bogotá, Colombia: Humanismo y Sociedad, Ltda.

García, A. (2006). El realismo dialéctico en la historia. (La crisis del marxismo como filosofía de interpretación de la historia -hacia el nuevo orden del hombre). Bogotá, Colombia: Ediciones Humanismo y sociedad.

García. A. (2006b). "Prólogo a la tercera edición". En La estructura del atraso en América Latina. Hacia una teoría latinoamericana del desarrollo. Bogotá, Colombia: Convenio Andrés Bello.

García, A. (2010). Los comuneros. Bogotá, Colombia: Ediciones Desde abajo.

Gil, N. (2005). Jusfilosofía en Luis Eduardo Nieto Arteta. En Memorias del Tercer Congreso Nacional. Bogotá, Colombia: Asociación Colombiana de Filosofía del Derecho y Filosofía Social.

Goldmann, L. (1979). Marxismo y ciencias humanas. Buenos Aires., Argentina: Amorrortu Editores.

Gómez, A. (2007). Nieto Arteta y la nueva lectura de la historia de Colombia. Magazín Del Caribe, 9 (junio).

Gómez, E. (2011). Memorias críticas de un estudiante de Humanidades en la Alemania socialista. Bogotá, Colombia: Universidad de Los Andes.

González Álvarez, L. J. (1988). "Equidad y justicia en el marco de la filosofía de la liberación”. (Ponencia inédita). II Encuentro Nacional de Investigadores en Recursos Humanos y Desarrollo. Bogotá, Colombia: Universidad de Santo Tomás. 
González Álvarez, L J. (1986). Ética Latinoamericana. Bogotá, Colombia: Universidad Santo Tomás.

Gracia, J. y Frondizi, R. (1981). El hombre y los valores en la filosofía latinoamericana del siglo XX. México: Fondo de Cultura Económica.

Gramsci, A. (1966). El materialismo histórico y la filosofía de Benedetto Croce. La Habana, Cuba: Ediciones Revolucionaria.

Granet, M. (1959). El pensamiento chino. México: UTEHA.

Guadarrama, P. (1986a). Valoraciones sobre el pensamiento filosófico cubano y latinoamericano. La Habana, Cuba: Editora Política.

Guadarrama, P. (1986b). Reflexiones sobre la filosofía de la liberación latinoamericana. Prometeo, II (6): 25-30.

Guadarrama, P. (1987). La evolución de las ideas de Leopoldo Zea como antecedente y pilar de la filosofía latinoamericana de la liberación. Revista Cubana de Ciencias Sociales, 13 (enero-abril).

Guadarrama, P. (1989). Por qué y para qué filosofar en América Latina? Liberacao, I (1): 30-40. Revista Cubana de Ciencias Sociales, (17): 22-34.

Guadarrama, P. (1989a). Hay crisis entre los marxistas latinoamericanos. Islas, 93.

Guadarrama, P. (1990). Marxismo y antimarxismo en América Latina. Bogotá, Colombia: Universidad INCCA de Colombia; segunda edición (1994), La Habana- México: Ediciones El Caballito, México-Editora Política; tercera edición (2015), Caracas, Venezuela: Editorial El Perro y la Rana. Ministerio de Cultura.

Guadarrama, P. (1992). Bases éticas del proyecto humanista y desalienador del pensamiento latinoamericano. En Memorias del Simposio "La utopía de América". Santo Domingo: Universidad Autónoma de Santo Domingo.

Guadarrama, P. (1993). (Direct. colectivo de autores). Humanismo y filosofía de la liberación en América Latina. Bogotá, Colombia: Editorial El Búho.

Guadarrama, P. (1993a). Antinomias de la crisis del socialismo. La Habana, Cuba: Editorial Ciencias políticas.

Guadarrama, P. (1994). América Latina, marxismo y postmodernidad. Bogotá, Colombia: Universidad INCCA de Colombia.

Guadarrama, P. (1994a). Mariátegui y la actual crisis del marxismo. La Gaceta de Cuba, (4): 34-38; Mariátegui en el pensamiento actual de nuestra América. En Coloquio Internacional convocado por la Casa de las América en La Habana. 
Lima, Peru: Empresa Editorial Amauta-Casa de las Ameritas. Cuadernos Casa. En línea: http://www.cialc.unam.mx/cuadamer/textos/ca137-125.pdf

Guadarrama, P. (1995). La dimensión concreta de lo humano en José Carlos Mariátegui. Coetapec, 4 (primavera-verano): 16-25.

Guadarrama, P. (1997). Humanismo y autenticidad en el pensamiento latinoamericano. . Bogotá, Colombia: Universidad INCCA de Colombia.

Guadarrama, P. (1998). Humanismo, marxismo y postmodernidad. La Habana, Cuba: Editorial Ciencias Sociales.

Guadarrama, P. (1998a). ¿Para qué filosofar? (Funciones de la filosofía). Revista de filosofía, (30): 109-139. En línea: http://www.filosofia.org/mon/cub/dt021.htm

Guadarrama, P. (1999). (Dir. de colectivo de autores). Despojados de todo fetiche. La autenticidad del pensamiento marxista en América Latina. Bogotá, Colombia: UNINCCA.

Guadarrama, P. (2000). Historia de la filosofía latinoamericana. (T. I). Bogotá, Colombia: Universidad Nacional Abierta a Distancia.

Guadarrama, P. (2000a). El lugar del componente ideológico en la filosofía y en el pensamiento político. En Guadarrama, P. Filosofía y Sociedad. (T. I y II) (Dir. de colectivo de autores). Editorial Félix Varela.

Guadarrama, P. (2001). Humanismo en el pensamiento latinoamericano. La Habana, Cuba: Editorial Ciencias Sociales; Tunja, Colombia: Universidad Pedagógica y Tecnológica de Colombia; Loja: Universidad Nacional de Loja-Universidad de Cuenca-Casa de la Cultura Ecuatoriana.

Guadarrama, P. (2001a). Filosofía, humanismo y alineación. Bogotá, Colombia: Universidad Nacional Abierta a Distancia. En línea: http://biblioteca.filosofia. $\mathrm{cu} /$ php/export.php?format $=$ htm\&id=105\&view $=1$

Guadarrama, P. (2001b). Positivismo en América Latina. Bogotá, Colombia: Universidad Nacional Abierta a Distancia.

Guadarrama, P. (2002). Posturas de Nietzsche y Marx ante la modernidad. En Cuestiones de Filosofía. Tunja, Colombia: Universidad Pedagógica y Tecnológica de Colombia.

Guadarrama, P. (2003). José Martí y el humanismo latinoamericano. Bogotá, Colombia: Convenio Andrés Bello.

Guadarrama, P. (2004). Positivismo y antipositivismo en América Latina. La Habana, Cuba: Editorial Ciencias Sociales. En línea: http://biblioteca.filosofia.cu/php/ export.php?format $=$ htm\&id $=231$ \&view $=1$ 
Guadarrama, P. (2005). Vida y muerte de la filosofía: Nietzsche y Marx. Actualidades, 12 (enero-junio). En línea: http://biblioteca.filosofia.cu/php/export. php?format=htm\&id=2569\&view $=1$

Guadarrama, P. (2005a). Autenticidad del pensamiento marxista de Ernesto Che Guevara Umbral._Revista de la Dirección Provincial de Cultura de Villa Clara, 18; Revista Cubana de Filosofía, 6 (mayo-septiembre). En línea: http://revista. filosofia.cu/default.php

Guadarrama, P. (2006). Cultura y educación en tiempos de globalización posmoderna. Bogotá, Colombia: Editorial Magisterio. En línea: http://biblioteca.filosofia.cu/php/export.php?format=htm\&id=2181\&view $=1$

Guadarrama, P. (2006a). Prólogo. En El realismo dialéctico en la historia. La crisis del marxismo como filosofía de interpretación de la historia. Hacia el nuevo orden del hombre, de Antonio García. Bogotá, Colombia: Ediciones Humanismo y Sociedad.

Guadarrama, P. (2006b). Humanismo y marxismo. En Marx Vive, (IV). Bogotá, Colombia: Universidad Nacional de Colombia; (Colectivo de autores). En Valqui Cachi, C. y Pastor Bazán, C. (Coord.). Marx y el marxismo crítico en el siglo XXI. México: Ediciones EON-Universidad Autónoma de Guerrero. En línea: http://es.scribd.com/doc/90507863/Cmilo-v-C-El-Marxismo-Critico.

Guadarrama, P. (2007). Crítica de los reduccionismos epistemológicos en las ciencias sociales. Aquelarre, 11 (I): 83-101; Revista Cubana de Ciencias Sociales. En línea: http://dialnet.unirioja.es/servlet/articulo?codigo=3384653

Guadarrama, P. (2007a). El marxismo estructuralista de Louis Althusser. Marx Ahora. Revista Internacional, 23.

Guadarrama, P. (2008). Pensamiento filosófico latinoamericano: Humanismo vs. Alienación. Caracas, República Bolivariana de Venezuela: Editorial El Perro y la Rana. Ministerio de Cultura. Tomo I, II y III.

Guadarrama, P. (2009a). Autenticidad. En Biagini H.E. y Roig, A.A. (Dir.). Diccionario del pensamiento alternativo. Buenos Aires, Argentina: Editorial Biblos.

Guadarrama, P. (2009b). Democracia y derechos humanos: ¿"Conquistas" exclusivas de la cultura occidental?. Nova et Vetera (II semestre): 79-96. En línea: http:// www.espaciocritico.com/

Guadarrama, P. (2009c). Cultura. En Biagini, H.E. y Roig, A.A. (Dir.). Diccionario del pensamiento alternativo. Buenos Aires, Argentina: UBA.

Guadarrama, P. (2011). Razones del positivismo y el antipositivismo sui géneris en América Latina. Cuadernos americanos, 3 (137). 
Guadarrama, P. (2012). La funcional interrelación epistemológica e ideológica entre filosofía, ética y política. En Álvarez, J.A. (Coord.). Aportes para una filosofía del sujeto, el derecho y el poder. Bogotá, Colombia:Universidad Libre.

Guadarrama, P. (2012a). Pensamiento Filosófico Latinoamericano. Humanismo, método e historia. (T. I). Bogotá, Colombia: Universitá degli Studi di SalernoUniversidad Católica-Planeta.

Guadarrama, P. (2012b). Pensamiento Filosófico Latinoamericano. Humanismo, método e historia. (T. II) . Bogotá, Colombia: Universitá degli Studi di SalernoUniversidad Católica-Planeta.

Guadarrama, P. (2012c). Razones del positivismo y el antipositivismo sui generis en América Latina. Cuadernos americanos, 3 (137): 125-149.

Guadarrama, P. (2013). Pensamiento Filosófico Latinoamericano. Humanismo, método e historia. (T. III). Bogotá, Colombia: Universitá degli Studi di SalernoUniversidad Católica-Planeta.

Guadarrama, P. (2014). El filosofar de Estanislao Zuleta y el marxismo. Aquelarre, 13 (26).

Guadarrama, P. (2014a). (Dir. de colectivo de autores). La condición humana en el pensamiento cubano del siglo XX. La Habana, Cuba: Editorial Ciencias Sociales. En línea: www.ensayistas.org/critica/generales/C-H/cuba

Guadarrama, P. (2014b). Democracia y los derechos humanos en los pueblos originarios de América. En XIV Simposio Internacional de Pensamiento Filosófico Latinoamericano. Santa Clara. Cuba: Facultad de Ciencias Sociales. Universidad Central de Las Villas.

Guadarrama, P. (2015). Marxismo y antimarxismo en América Latina. Crisis y renovación del socialismo. Caracas, Venezuela: Editorial El Perro y la Rana. Ministerio de Cultura. En línea: http://www.elperroylarana.gob.ve/images/libros-pdfs/ AM-Volumen1.pdf

Guadarrama, P. (2015a). José Martí: humanismo práctico y latinoamericanista. Santa Clara: Editorial Capiro.

Guadarrama, P. (2016). Democracia y derechos humanos: visión humanista desde América Latina. Bogotá, Colombia: Taurus; Peguin Random House. Tomo I.

Guadarrama, P. (2016a). Democracia y derechos humanos: visión humanista desde América Latina. Bogotá, Colombia: Taurus; Peguin Random House. Tomo II.

Guadarrama, P. y Tussel, E. (1987). El pensamiento filosófico de Enrique José Varona. La Habana, Cuba: Editora Ciencias Sociales. 
Guadarrama, P.; Rivero, D. M. Rojas; Lourdes R.; Fleites, M. (1988). El positivismo y el materialismo científico natural en Latinoamérica. En La filosofía en México, Siglo XX. Tlaxcala: Universidad Autónoma de Tlaxcala.

Guadarrama, P. y Pereliguin, N. (1989). Lo universal y lo específico en la cultura. Bogotá, Colombia: Universidad INCCA de Colombia; La Habana, Cuba: Editorial Ciencias Sociales.

Guadarrama, P. y Machado, L. (2014). Antonio García Nosa y/en las ciencias sociales en América Latina: el conflicto ciencia e ideología. En Amauta. Barranquilla, Colombia: Universidad del Atlántico.

Guadarrama, P. y Maddaloni. D. (2016). Le origini della sociología in America Latina. Eugenio María de Hostos ed Enrique José Varona. Salerno: Ipermedium libri.

Guevara, E. (1997). Carta a Armando Hart Dávalos. 4 de diciembre de 1965. Contracorriente. Una revista cubana de pensamiento. La Habana, Cuba.

Hoyos, G. (1983). “Elementos para una interpretación filosófica del joven Marx”. En In Memoriam Marx 1883-1983. Bogotá, Colombia: CINEP.

Habermas, J. (1992). Ciencia como técnica y como ideología. Madrid, España: Tecnos. Hartman, N. (1963). Ontología. En Marías, J. La filosofía en sus textos. (T. III).

Hegel, G. F. (1968). Enciclopedia de las ciencias filosóficas. La Habana, Cuba: Editorial Estudios.

Hegel. G. F. (1955). Lecciones sobre la historia de la filosofía. México: Fondo de Cultura Económica.

Hegel. G. F. (1972). Fenomenología del espíritu. La Habana, Cuba: Editorial Ciencias Sociales.

Helvetius, C. A. (1973). De l' esprit. Belgique: Maraboute Université.

Hernández, E. (1987). La filosofía de la liberación: la universalidad del sujeto. En Ponencia presentada al Congreso Internacional Extraordinario de Filosofía. Córdoba, Argentina.

Herrera, D. (1988a). Nosotros y la fenomenología. En Tendencias Actuales de la Filosofía en Colombia. Bogotá, Colombia: USTA.

Herrera, D. (1988b). La filosofía en la Colombia contemporánea (1930-1988). En Marquínez, G. y otros. Bogotá, Colombia: El Búho.

Herrera, D. (1986). Escritos sobre fenomenología. Bogotá, Colombia:Universidad Santo Tomás, 
Hobbes, T. (s.f.). Leviatán. En línea: http://www.uruguaypiensa.org.uy/imgnoticias/749.pdf

Holbach, P. H. (1989). Sistema de la naturaleza. La Habana, Cuba: Editorial Ciencias Sociales.

Holbach. P.H. (1982). Ensayos sobre los prejuicios. En La ideología en sus textos. (Selección de Armando Cassigoli y Carlos Villagrán). México: Marcha Editores.

Holguín, M. (1988). Recepción e incidencia de la filosofía analítica. En Tendencias actuales de la filosofía en Colombia. Bogotá, Colombia: USTA.

Hoyos, G. (1986) Los intereses de la vida cotidiana y la ciencia. Bogotá, Colombia: Universidad Nacional. En línea:

http://marxismocritico.files.wordpress.com/2012/10/mega.pdf

http://www.archivochile.com/Ideas_Autores/guadarramapg/guadarramapg00001.pdf

Husserl, E. (1967). Investigaciones lógicas. Madrid, España: Revista de Occidente.

Iglesias, S. (1981). Ciencia e ideología. México: Editorial Tiempo.

Insua, F. (1959). Historia de la filosofía en Hispanoamérica. Quito, Ecuador: Imprenta de la Universidad de Guayaquil; Editorial Casa de la Cultura.

Isaza, G. (1990). Estanislao Zuleta: Un pensador solitario. En Bustamante, G; García, J; Giraldo, F. y otros. Tunja: Ediciones la Rana y el Águila.

Jameson, F. (1999). Apuntes sobre la globalización como problema filosófico. En Castro-Gómez, S. y otros. Pensar en los intersticios. Teoría y práctica de la crítica postcolonial. Bogotá, Colombia: Pensar, Pontificia Universidad Javeriana.

Jaramillo, J. (1964). El pensamiento colombiano en el siglo XIX. Bogotá, Colombia: Temis.

Jaramillo Vélez, R. (1988). Recepción e incidencias del marxismo en Colombia. En Tendencias actuales de la filosofía en Colombia. Bogotá, Colombia.

Jaramillo, D. (2007). Satanización del socialismo y del comunismo en Colombia 19301953. Popayán, Colombia: Editorial Universidad del Cauca.

Kant, E. (1973). Crítica de la razón pura. La Habana, Cuba: Editorial Ciencias Sociales.

Kempf, M. (1958). Historia de la filosofía en Latinoamérica. Santiago de Chile. (s.e.).

Klaus, G.y Buhr, M. (1970). Philosophisches Wörterbuch. Leipzig, Deutschland: VEB Bibliographisches Institut,

Kohan, N. (1998). Marx en su (Tercer) Mundo Hacia un socialismo no colonizado. Buenos Aires, Argentina: Biblos. 
Kuusinen, O. y otros (1964). Fundamentos de marxismo-leninismo. Moscú, Rusia: Editorial Progreso.

Laercio, D. (1990). Vida de los filósofos más ilustres. La Habana, Cuba: Editorial Ciencias Sociales.

Lakatos, I. (1983). La metodología de los programas de investigación científica. Madrid, España: Alianza Editorial.

Lenin, V.I. (1959). Carta a la Agrupación del norte. En Obras Completas. Buenos Aires, Argentina: Editorial Cartago.

Lenin, V.I. (1959a). Notas sobre el materialismo militante. En Lenin, Obras Escogidas. (Vol. I). Moscú, Rusia: Editorial Progreso.

Lenin. V. I. (1959b). El censo de los kustares de 1894-1895. En Obras Completas. La Habana, Cuba: Editora Política.

Lenin. V.I. (1959c). Vicisitudes históricas de la doctrina de Carlos Marx. En Obras Completas. La Habana, Cuba: Editora Política.

Lenin.V.I. (1959d). La agitación política y el punto de vista de clase. En Obras Completas. La Habana, Cuba: Editora Política.

Lenin, V.I. (1963a). Programa agrario de la socialdemocracia. En Obras Completas. La Habana, Cuba: Editora Política.

Lenin, V.I. (1963b). Acerca de la fracción de los Vperiod. En Obras Completas. La Habana, Cuba: Editora Política.

Lenin, V.I (1965). Materialismo y empiriocriticismo. En Obras Completas. La Habana, Cuba: Editora Política.

Liss, B. S. (1984). Marxist Thought in Latin America. London: University California Press, Berkeley, Los Angeles.

Lyotard, F. (1989). La condición posmoderna. México: Ediciones Rei.

Machado, L. (2006). Aproximación al concepto de democracia en Antonio García. Pensamiento latinoamericano, 3.

Machado, L. y Guadarrama, P. (2008). Antonio García: concepción antropológica y humanismo práctico. Aquelarre, 13 (I).

Magallón, M. (1985). Filosofía de circunstancia. Prometeo, 3 (2).

Manifiesto del Partido Comunista. En línea: http://www.marxists.org/espanol/m-e/1840s/48-manif.htm.

Mannheim, K. (1958). Ideología y utopía. Introducción a la sociología del conocimiento. Madrid, España: Edit. Aguilar. 
Mantilla Pineda, B. (1956). La muerte absurda de Luis Eduardo Nieto Arteta. Revista Universidad de Antioquia, 126 (3).

Marco Aurelio. (1956). Los doce libros. Buenos Aires, Argentina: Ediciones TOR.

Marcuse, L. (1947). Filosofía americana. Madrid, España: Editorial Guadarrama, S.A.

Marías, J. (1963). La filosofía en sus textos. Editorial Labor.

Mariátegui, J.C. (1985). “Defensa del marxismo”. (T.V). En Colección Obras Completas. Lima, Perú: Amauta.

Márquez, P.J. (1962). “El filósofo, ciudadano del mundo”. En Humanistas del_siglo XVIII. Introducción y selección Gabriel Méndez Plancarte. México: UNAM.

Marquínez, G. et all. (1990). El hombre latinoamericano y sus valores. Bogotá, Colombia: Editorial Nueva América.

Marquínez, G. (1982). Filosofía de la ilustración en Colombia. Bogotá, Colombia: Editorial El Búho.

Marquínez, G. (1986). Filosofía de la religión. Bogotá, Colombia: Universidad Santo Tomás.

Marquinez, G. (1994). Metafísica desde Latinoamérica. Bogotá, Colombia: Universidad Santo Tomás.

Marquínez , G. (1987). Sobre filosofía española y latinoamericana. Bogotá, Colombia: Universidad Santo Tomás.

Marquínez, G. Salazar, R. Rodríguez, E. y otros (1997). La filosofía en Colombia. Bogotá, Colombia: El Búho.

Martí, O. (1984). “Historia y filosofía de nuestra América”. Prometeo, 1 (4).

Martí. J. (1973). Obras completas. La Habana, Cuba: Ciencias Sociales.

Marx, C. (1965). Manuscritos económicos y filosóficos de 1844. La Habana, Cuba: Editora Política.

Marx, C. y F. Engels. (1955). Obras Escogidas. Moscú, Rusia: Ediciones en lenguas extranjeras.

Marx, C. (1972). Miseria de la filosofía. Moscú, Rusia: Editorial Lenguas Extranjeras.

Marx, C. (1975), El capital: critica de la economía política. México: Ediciones Siglo XXI.

Marx, C. (1975a). Carta a Kugelmann. 11 de julio de 1868. En Marx, C. Cartas a Kugelmann. La Habana, Cuba: Editorial Ciencias Sociales. 
Marx. C. (1976). Crítica del derecho político hegeliano. La Habana, Cuba: Editora Política.

Marx, C. (1982). El 18 de Brumario de Luis Bonaparte. En Marx, C. y Engels, F. Obras Escogidas. (T. II). Moscú, Rusia: Editorial Progreso.

Marx, C. (1991). Tesis doctoral. En Marx, C. y Engels, F. Categorías fundamentales (1836-1844). Caracas, Venezuela: Ediciones del Rectorado de la Universidad Central de Venezuela.

Marx, C. (1992). Sobre la cuestión judía. (Trad: Rubén Jaramillo Vélez). Bogotá: Argumentos.

Marx, C y F. Engels. (1965a). La sagrada familia. La Habana, Cuba: Editora Política.

Marx, C. y F. Engels. (1965b). La ideología alemana. La Habana, Cuba: Editora Revolucionaria.

Masson-Oursel, P. y otros. (1957). La India antigua y su civilización. México:

UTEHA.

Meisel, A. (2004). Prólogo a Nieto Arteta, Luis Eduardo. En Cataño, G. (Comp.). Crítica a la economía política. Ensayos. Bogotá, Colombia: Universidad Externado de Colombia.

Melo, O. (1968). "La literatura histórica en la Republica”. En Manual de literatura colombiana. Bogotá, Colombia: Planeta.

Merquior, J.G. (1987). O marxismo ocidental. Rio de Janeiro, Brasil: Editora Nova Fronteira. Miró, F. (1953). Conversaciones filosóficas interamericanas. La Habana, Cuba.

Miró, F. (1968). El impacto de la metafísica en la ideología latinoamericana contemporánea. México.

Misas, G. (1944). El marxismo y las investigaciones económicas en Colombia. En Fals Borda; Molina, O; Fajardo, G y otros. El marxismo en Colombia. Bogotá, Colombia: Universidad Nacional de Colombia.

Miscellaneous. (1883). El espíritu de los Upanischadas. Buenos Aires: Ediciones Caballero.

Molina, G. (1987). Las ideas socialistas en Colombia. Bogotá, Colombia: Tercer Mundo.

Moncayo. V. M. (1998). "Prólogo”. En Valencia, L. E. El pensamiento económico en Jorge Eliécer Gaitán. Bogotá, Colombia: EUN. 
Mondolfo, R. (1971). El pensamiento antiguo. La Habana, Cuba: Editorial Ciencias Sociales.

Morales, E. (1988). Poder e saber, saber e poder no seculo XVI. Uma análise sobre o caso Copérnico. En Uma história da filosofía. Razáo e mística na ideade media. Rio de Janeiro, Brasil: Universidade Federal do Rio de Janeiro-Universita Universidade Aberta.

Moro, T. Campanella, T. y Bacon, F. (1956). Utopías del Renacimiento._México: Fondo de Cultura Económica.

Naranjo, A. (1988). La influencia española en la secularización de la filosofía en Colombia. En Tendencias actuales de la filosofía en Colombia. Bogotá, Colombia: Universidad Santo Tomás.

Nieto, L.E. (1932). Revista Jurídica, XXIV (225-226).

Nieto, L.E. (1934). Revista Jurídica. (234).

Nieto, L.E. (1939). Derecho. Revista del Colegio de Abogados, XIII (49).

Nieto, L.E. (1940). Posibilidad teórica de un marxismo spengleriano, 42. Medellín, Colombia: Universidad de Antioquia.

Nieto, L.E. (1941a). Lógica, fenomenología y formalismo jurídico, 7. Medellín, Colombia: Universidad Católica Bolivariana.

Nieto, L.E. (1941b). El hombre, la vida, la cultura y el derecho, VII (22). Medellín, Colombia: Universidad Católica Bolivariana.

Nieto, L.E. (1942). La filosofía de Francisco Romero, 55. Medellín, Colombia: Universidad de Antioquia.

Nieto, L.E. (1946). Guillermo Dilthey, 6. Colombia: Universidad Nacional de Colombia.

Nieto, L.E. (1943). Revista del Colegio de Abogados, XVIII, (64-65). Medellín, Colombia.

Nieto, L.E. (1950). Lógica, ontología y gnoseología. Actas del Primer Congreso Nacional de Filosofía. Buenos Aires, Argentina: Universidad Nacional de Cuyo.

Nieto, L.E. (1957). Dialéctica de la razón. Diario del Caribe. Hojas literarias. Suplemento cultural.

Nieto, L.E. (1962). Economía y cultura en la historia de Colombia. Bogotá, Colombia: Ediciones tercer Mundo. 
Nieto, L.E. (1978a). La bomba atómica y sus consecuencias políticas. (1945). En Ensayos históricos y sociológicos. Bogotá, Colombia: Instituto Colombiano de Cultura.

Nieto, L.E. (1978b). Dos dialécticas: Marx y Proudhon. (1941). En Ensayos históricos y sociológicos, Bogotá, Colombia: Instituto Colombiano de Cultura.

Nieto, L.E. (1978c). Forma y contenido en la obra de López de Mesa. (1944). En Ensayos históricos y sociológicos. Bogotá, Colombia: Instituto Colombiano de Cultura.

Nieto, L.E. (1978d). Una muy falsa historia de América. (1946). En Ensayos históricos y sociológicos. Bogotá, Colombia: Instituto Colombiano de Cultura.

Nieto, L.E. (1983a). Lógica y ontología. Barranquilla, Colombia: Ediciones del Cincuentenario del Atlántico,

Nieto, L.E. (1983b). Economía y cultura en la historia de Colombia. Bogotá, Colombia: El Ancora Editoras.

Nieto, L.E. (1983c). En defensa del pensamiento de Marx. (1933). En Ensayos históricos y sociológicos. Bogotá, Colombia: Instituto Colombiano de Cultura.

Nieto, L.E. (1985). Ontología de lo social. En La filosofía en Colombia. Siglo XX. Bogotá, Colombia: Procultura.

Nieto, L. E. (1994). Cartas de amor de Neto Arteta. Barranquilla, Colombia: Ediciones Gobernación del Atlántico.

Nieto, L.E. (2004). Crítica a la economía política. Ensayos, Gonzalo Cataño compilador. Bogotá, Colombia: Universidad Externado de Colombia.

Nieto. F. (2008). Los dilemas de Nieto Arteta. Barranquilla, Colombia.

Nietzsche, F. (1951). Más allá del bien y el mal. Obras Completas de Federico Nietzsche. Buenos Aires,: Argentina Aguilar.

Nietzsche, F. (1957). “Tratados filosóficos”. En Obras Completas de Federico Nietzsche. Buenos Aires, Argentina: Aguilar.

Nietzsche, F. (1957). Filosofía general. Obras completas de Federico Nietzsche. Buenos Aires, Argentina: Aguilar.

Nuñez, J. (2004). La ciencia en el encuentro entre ética y epistemología. En López Bombino, L. (Comp.). (Colectivo de autores). Por una nueva ética. La Habana, Cuba: Editorial Félix Varela.

Nuñez, T, J. R. (1976). Teoría y método de la economía política marxista. Caracas, Venezuela: Universidad Central de Venezuela. 
Oizermann, T. y otros (1980). Geschichte del Dialektik. Berlin, Deutschland: Dietz Verlag.

Ortiz, H. (2007). Derechos humanos. Bogotá, Colombia: Grupo Editorial Ibáñez.

Ortiz, H. (2008). Nieto Arteta y la filosofía moderna en Colombia. En Ortiz, H. (Coord.). Pioneros de la filosofía moderna en Colombia (siglo XX). Bogotá, Colombia: Editorial Ibáñez.

Osvaldo, A. (1988). El exilio de la razón. Córdoba, Argentina: Sils-María.

Pachón, D. (2011). Estudios sobre el pensamiento colombiano. Bogotá, Colombia: Ediciones Desde Abajo.

Pachón, D. (2015). Estudios sobre el pensamiento filosófico latinoamericano. Bogotá, Colombia: Ediciones Desde Abajo.

Piedrahita, J. (1973). Prólogo a La hora cero de la universidad colombiana. Medellín, Colombia.

Plá, R. (1989). Marxismo, ¿eurocentrismo o universalidad?. En Ponencia presentada al II Simposio sobre Pensamiento Filosófico Latinoamericano de la Universidad Central de Las Villas. Santa Clara.

Platón. (1946). Gorgias o de la retórica. En Obras Completas. Buenos Aires, Argentina: Ediciones Anaconda.

Platón. (1968). La República. Madrid, España: Editorial Aguilar.

Platón. (1946). Obras Completas de Platón. Buenos Aires, Argentina: Ediciones Anaconda.

Ponencias, actas y seminarios. (1984). III Congreso Internacional de Filosofía latinoamericana. Bogotá: Universidad Santo Tomás,

Popol Vuh. (1975). La Habana, Cuba: Editorial Casa de las Américas.

Popper, K. (1997). El mito del marco común. En defensa de la ciencia y la racionalidad. Barcelona, España: Paidos Básica.

Proyecto internacional de investigación. (s.f.). El pensamiento latinoamericano del siglo XX ante la condición humana. En línea: www.ensayistas.org/critica/ generales/C-H/

Púa Mora, F.G. (2011). “Filosofías amerindias: búsqueda de lo propio en América Latina. Seria Filosófica, 16.

Rabossi, E. (1984). Enseñar filosofía y aprender a filosofar. Cuadernos de Filosofía $y$ Letras, 3-4. 
Reichenbach, H. (1975). La filosofía científica. En Reichenbach, H. La filosofía científica. México: Fondo de Cultura Económica. Fondo de Cultura Económica. Revista de filosofía. Centro de Estudios Filosóficos “Adolfo García Díaz”. Universidad del Zulia.( 2000, 2001, 2002). Filosofía y Sociedad. (Tomo I) (Dir. de colectivo de autores). La Habana, Cuba: Editorial Félix Varela.

Rivero, D. Rojas, M. Rensoli, L. Fleites, M. y Guadarrama, P. (1988). “El positivismo y el materialismo científico natural en Latinoamérica”. En La filosofía en México. Tlaxcala: Siglo XX, Universidad Autónoma de Tlaxcala.

Rodríguez, E. (1981). Introducción a la filosofía latinoamericana. Bogotá, Colombia: Universidad Santo Tomás.

Rodríguez, E. (1985). Marx y América Latina. Bogotá, Colombia: Editorial El Búho.

Roig, A.A. (2002). Ética del poder y moralidad de la protesta. La moral latinoamericana de la emergencia. Quito, Ecuador: Universidad Andina Simón Bolívar.

Roig. A.A. (1984). Cuatro tomas de posición. Nuestra América, 11 (2).

Ross, W. (1954). Crítica a la filosofía cubana de hoy. En Cuadernos de la UNESCO. La Habana, Cuba: UNESCO.

Rousseau, J. J. (1973). Sobre si el descubrimiento de las ciencias y de las artes han contribuido al mejoramiento de las costumbres. Obras. Editorial Ciencias Sociales. La Habana, Cuba.

Rousseau, J.J (1973). Obras escogidas. La Habana, Cuba: Editorial de Ciencias Sociales.

Rubel, M. (1974). Páginas escogidas de Marx para una ética socialista. Buenos Aires, Argentina: Amorrortu Editores.

Rubio, J. (1982). La filosofía en Colombia una crisis que da que pensar. Cuadernos de Filosofía Latinoamericana, 12.

Sabater, F. (1999). “Lo universal y lo nacional: valores ético políticos hoy”. En Filosofía del derecho, ética, cultura y constitución. Bogotá, Colombia: Ediciones Jurídicas Gustavo Ibáñez.

Sabogal, J. (2004). El pensamiento económico de Antonio García. Paradigma de independencia intelectual. Bogotá, Colombia: Editorial Plaza y Janés.

Salazar Bondy, A. (1969). ¿Existe una filosofía de nuestra América? México: Editorial Siglo XXI.

Salazar, R. (1986). “Acerca de la filosofía latinoamericana en la última década en Colombia". Cuadernos de filosofía latinoamericana, 28-29.

Sánchez, F, Guadarrama. P. (1988). Ideologización o desideologización en el estudio de la cultura latinoamericana. Islas, 89-92. 
Sánchez Reulet, A. (1949). La filosofía latinoamericana contemporánea. Washington, EE.UU: Unión Panamericana.

Sánchez Reulet, A. (1953). Conversaciones filosóficas interamericanas. La Habana, Cuba: Sociedad Cubana de Filosofía.

Sánchez Vázquez, A. (1975). Filosofía de la praxis. México: Editorial Grijalbo

Sánchez Vázquez, A. (1982). Ciencia y Revolución. El marxismo de Althusser. México: Editorial Grijalbo.

Sánchez Vázquez, A. (1987). Escritos de política y filosofía. Madrid, España: Editorial Ayuso.

Sánchez, F. y Guadarrama, P. (1988). Ideologización o desideologización en el estudio de la cultura latinoamericana. Islas, 89.

Santacruz, F. Círculo de estudios económicos sociales Antonio García. (inédito).

Sanz, J. (1985). Educación y liberación en América Latina. Bogotá, Colombia: Universidad Santo Tomás.

Sartre, J.P. (1963). Cuestiones de Método. En Crítica de la razón dialéctica. Buenos Aires, Argentina: Editorial Losada.

Schaff, A. (1980). Ideología y marxismo. México: Editorial Grijalbo.

Schumpeter. J. (1968). Ciencia e ideología. Buenos Aires, Argentina: EUDEBA.

Schutte, O. (1987).Orígenes y tendencias de la filosofía de la liberación en el pensamiento latinoamericano. Prometeo, enero-abril.

Sciacca, F. M. (1959). Las grandes corrientes del pensamiento contemporáneo. Madrid, España: Ediciones Guadarrama.

Séneca. (1963). “De la vida bienaventurada”. En Marías, J. La filosofía en sus textos. Madrid, España: Editorial Labor.

Sierra, R. (1987). Apreciación de la filosofía analítica. Bogotá, Colombia: Universidad Nacional de Colombia.

Sierra, R. (1978). Ensayos filosóficos. Bogotá, Colombia: Editora Instituto Colombiano de Cultura.

Sierra, R. (2002). Ensayos impopulares. Manizales, Colombia: Editorial Universidad de Caldas.

Sierra, R. (1978). Nota sobre la filosofía del derecho de Nieto Arteta. Bogotá, Colombia: Ensayos filosóficos, Ed. Andes.

Silva Colmenares, J. (1983). Tras la máscara del subdesarrollo: dependencia y monopolios. Bogotá, Colombia: Carlos Valencia Editores. 
Silva, L. (1984). La plusvalía ideológica. Caracas, Venezuela: Universidad Central de Venezuela.

Silva, L. (1977). Teoría y práctica de la ideología. México: Editorial Nuestro Tiempo.

Stuart Mill, J. (1987). Sobre la libertad. San José de Costa Rica, Costa Rica: Universidad Autónoma de Centroamérica..

Tamayo, J. (2012). Invitación a la utopía. Estudio histórico para tiempos de crisis. Madrid, España: Trotta.

Toffannin, G. (1953). Historia del humanismo desde el siglo XIII hasta nuestros días. Buenos Aires, Argentina: Ediciones Nova.

Toffler, A. (1973). El Schock del futuro. Barcelona, España: Plaza y Janes. Editores.

Tovar, L. (1988). Tradicionalismo y neo escolástica. En Marquínez, A. y otros. La filosofía en Colombia. El Búho.

Tracy, D, de. (1824). Eléments d’ ideologie. Paris, France : Chez Mme Levi. Libraire.

Trías, E. (1975). Teoría de las ideologías. Barcelona, España: Editorial Península.

Turner, R. (1979). Las grandes culturas de la humanidad. La Habana, Cuba: Ediciones Revolucionaria.

Valencia, A. (1996). En el principio era la ética... ensayo de interpretación del pensamiento de Estanislao Zuleta. Cali, Colombia: Universidad del Valle.

Valencia, L. E. (1968). Prólogo. En Gaitán, J. Antología de su pensamiento económico y social. Bogotá, Colombia: Ediciones Suramérica.

Valencia, L. E. (1998). El pensamiento económico en Jorge Eliécer Gaitán. Bogotá, Colombia: Editorial Univerdad Nacional.

Vargas, G. (1990). ¿Qué hacer con la filosofía en América Latina? México: Universidad Autónoma Metropolitana.

Vargas, R. (1992). Ética y marxismo. En Camps, V, Guariglia, O. y Salmerón, F. Concepciones de la ética. Enciclopedia Iberoamericana de Filosofía. Madrid, España: Editorial Trotta.

Vasconcelos, J. (1929). Metafísica. México: Editorial México joven.

Vattimo. G. (1990). El fin de la modernidad. Barcelona, España: Gedisa.

Villamizar, J.C (2007). Antonio García Nosa. En Castro-Gómez S., Flores Malagón, A, Hoyos, G. Castro. S. y Millán de Benavides, C. (Edit.). Pensamiento colombiano del siglo XX. Bogotá, Colombia: Instituto Pensar. Pontificia Universidad Javeriana. 
Villoro, L. (1985). El concepto de ideología en Sánchez Vázquez. En Praxis y filosofía. Ensayos en homenaje a Adolfo Sánchez Vázquez. México: Grijalbo.

Villoro, L. (1982). Creer, saber, conocer. México: Siglo XXI.

Vollpe, G. de la. (1967). Rousseau y Marx y otros ensayos de crítica materialista, La Habana, Cuba: Editora Política.

Voltaire, F. (1986). Diccionario filosófico. Antología de Historia de la Filosofía. La Habana, Cuba: Universidad de La Habana.

Weber, M. (1959). El político y el científico. Madrid, España: Alianza Editorial.

Windelband, W. (1943). Historia de la filosofía. México: Antigua Librería Robredo.

Zabalza, J. (1988). La filosofía colonial. Nuestra tardía edad media. En La filosofía en Colombia, Historia de las ideas. Bogotá, Colombia: Editorial El Búho.

Zea, L. (1957). América en la historia. México: FCE,

Zea, L. (1965). El pensamiento latinoamericano. Lima, Perú: Editorial Pormaca.

Zea, L. (1976). Filosofía y cultura Latinoamérica. Caracas, Venezuela: Centro de Estudios latinoamericanos "Rómulo Gallegos”.

Zea, L. (1969). La filosofía americana como filosofía sin más. México: Editorial Siglo $\mathrm{XI}$.

Zuleta, E. (1972). Comentarios a la Introducción a la crítica de la economía política (Manuscritos de 1857). Apéndice. Sobre la teoría del reflejo. Medellín, Colombia: Universidad de Antioquia.

Zuleta, E. (1987) Ensayos sobre Marx. Medellín, Colombia: Percepción.

Zuleta E. (1989). Conferencia de Estanislao Zuleta en el campamento del M 19. 14 de mayo de 1989. (s.d.).

Zuleta, E. (1995). Educación y democracia. Un campo de combate. Cali, Colombia: Corporación Tercer Milenio-Fundación Estanislao Zuleta.

Zuleta, E. (2003). Lógica y crítica. Lecciones de filosofía. Medellín, Colombia: Hombre Nuevo Editores.

Zuleta, E. (2008). Conversaciones con Estanislao Zuleta. Medellín, Colombia: Hombre Nuevo Editores EU.

Zuleta, E. (2010). “Marxismo y psicoanálisis”. En Tres culturas, tres familias y otros ensayos. Bogotá, Colombia: Hombre Nuevo Editores.

Zuleta E. (2011). Elogio de la dificultad y otros ensayos. Medellín, Colombia: Hombre Nuevo Editores. 


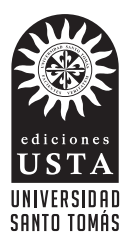

Esta obra se editó en Ediciones USTA,

Departamento Editorial de la Universidad Santo Tomás.

Se usó papel propalcote de 300 gramos para la carátula y papel bond beige de 75 gramos para páginas internas.

Tipografía Sabón Lt Std.

Impreso por Image Printing Ltda.

2017. 
Las funciones de la filosofía, así como sus nexos epistemológicos con la ideología, la ética y la política, han sido y serán objetos permanentes de valoración por amplios sectores intelectuales, entre los cuales se encuentran algunas personalidades colombianas y latinoamericanas, estudiadas en este libro. Cada uno tuvo relaciones muy diferentes respecto a la filosofía. Sin embargo, todos ellos hicieron de la filosofía un instrumento epistémico de extraordinario valor. No faltarán quienes, con criterios esquemáticos de lo que es un filósofo, podrían cuestionarse su condición de poseer tal calificativo. Lo importante no es tanto si sus nombres deben estar o no en una selecta galería de filósofos. Lo que los hace meritorios de ser objeto de estudio es que todos ellos hicieron de la filosofía un indispensable instrumento de análisis para tratar de comprender y sobre todo transformar sus respectivas circunstancias. Supieron aportar ideas de valor que hoy deben ser tomadas en digna consideración porque trascienden a sus épocas. Esto ya es motivo suficiente para que tales ideas estén disponibles en el instrumental epistemológico, axiológico y práctico en la labor intelectual y académica que hoy nos corresponde y que necesariamente deben asumir las nuevas generaciones. Los debates sobre la autenticidad de la vida filosófica de Nuestra América, al parecer superados, siempre afloran de nuevo, como para indicar que esta se debe continuar construyendo. 